\title{
Ideología y configuración descortés de la imagen de Pablo Iglesias y otros políticos de Podemos en los medios de comunicación españoles
}

María Bernal

Stockholm University

\section{Introducción}

El panorama político español fue testigo durante 20I4 de una situación convulsa propiciada por la aparición de Podemos como partido político que en solo cuatro meses avanzó de su creación en enero de 2014 a la obtención de cinco escaños en las elecciones al Parlamento Europeo de mayo del mismo año. Posteriormente, Podemos subió rápidamente cotas en las medidas de intención de voto (CIS, julio de 20I $4^{\mathrm{I}}$ ) y resultó la tercera fuerza política en las elecciones de diciembre de 2015 y de junio de 2016 (en esta última ocasión en la coalición Unidos Podemos con los partidos de izquierda Izquierda Unida y Equo).

Frente a este nuevo actor en el panorama político español ${ }^{2}$, el posicionamiento discursivo elegido por parte de representantes tanto de la política como de los medios de comunicación trató a menudo la presentación de la imagen de Pablo Iglesias, líder de Podemos, desde el escarnio y la ridiculización (cf. Bernal 20I4): ataques a su imagen personal y profesional con apodos peyorativos como "el Coletas",

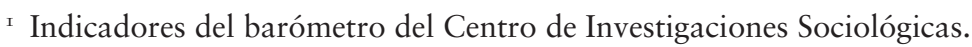

Abril de 20I4: http://www.cis.es/cis/opencms/ES/II_barometros/indicadores. html

Abril de 20I7: http://www.cis.es/cis/opencms/ES/I I_barometros/Indicadores_PI/ documentos/B6060500Ioa.html

2 Véase Alcaide (en este volumen) para una comparación entre los estilos discursivos de rasgos populistas de los líderes de los partidos “emergentes” Podemos (Pablo Iglesias) y Ciudadanos (Albert Rivera).

Cómo citar este capítulo:

Bernal, M. 20I9. "Ideología y configuración descortés de la imagen de Pablo Iglesias y otros políticos de Podemos en los medios de comunicación españoles”. In: Françoise Sullet-Nylander, María Bernal, Christophe Premat \& Malin Roitman (eds.). Political Discourses at the Extremes. Expressions of Populism in Romance-Speaking Countries. Stockholm Studies in Romance Languages. Stockholm: Stockholm University Press, pp. I75-200. DOI: https://doi.org/IO.I6993/bax.i. License: CC-BY 
"friki", "miserable" (debate televisivo Al rojo vivo), "estrella catódica" (J. González, $A B C^{4}$ ), "Iglesias opta por la koleta borroka"; críticas a su ropa "barata y descuidada" ${ }^{6}$ y se le achaca poca higiene (en el diario La razón). También se han realizado ataques a su imagen política llamando a Iglesias "populista mamarracho"7 y “el rojeras más mediático del país" (F. Marhuenda ${ }^{8}$ ) y estableciendo paralelismos entre Podemos y las campañas informativas nazis y comunistas, así como su afinidad a regímenes totalitarios -el chavismo de Venezuela- y al terrorismo ETA- (columna de opinión del diario $A B C$; blog de Esperanza Aguirre9, política del Partido Popular, cf. $\$$ 5.I).

En este trabajo analizamos una muestra de diferentes tipos de discurso de la escena mediática (Charaudeau 2005), como columnas de opinión y extractos de debates televisivos, con el objetivo de profundizar en el uso estrategias discursivas de descalificación del adversario político. Considerando las actividades de imagen como estrategias argumentativo-discursivas (Bravo 2015), nos centraremos en actividades de ataque a la imagen personal de Pablo Iglesias y de otros integrantes del partido Podemos como muestra de una descortesía de fustigación (Kaul de Marlangeon 2005) basada en insultos (Bolívar 2005) y argumentos falaces de corte emocional, como los argumentos ad hominem (Kienpointner 2008). Estas estrategias, que suponen una suerte de demonización de Podemos y sus miembros, han sido usadas predominantemente por políticos y simpatizantes de la derecha; el fin político ulterior que vislumbramos, en lo que se podría llamar descortesía ideológica de fustigación, es el descrédito del partido Podemos,

3 Fórum Europa con José Juan Toharia y Pedro Arriola, en http://ponss.blogs.uv.es/ 20I4/og/I 4/friki-de-armas-tomar/ (cf. Pons 20I4).

427 de mayo de 20I4. https://www.libertaddigital.com/espana/20I4-05-27/ marhueda-quiere-echar-a-el-coletas-de-la-sexta-I 2765 I9730/

5 En un juego de palabras con kale borroka. http://www.elmundo.es/opinion/2016/ Io/2 I/5809 I 5 Ib268e 3e2f698b46e4.html

${ }^{6}$ En 'La Gaceta. La información alternativa': "Pablo Iglesias se compra la ropa en Alcampo", http://www.gaceta.es/josef/pablo-iglesias-compra-ropa-alcampo260520I4-I 838 26/05/20I4

"Las pulseras de cuero de Pablo Iglesias le llegan ya al codo": http://www.elmundo. es/loc/20I6/Io/29/58I3727ce5fdea I I 6f8b4590.html

7 Intereconomía, en http://ponss.blogs.uv.es/20I4/og/I4/friki-de-armas-tomar/ (cf. Pons 20I4).

${ }^{8}$ https://www.estrelladigital.es/articulo/television/razon-carga-atresmedia/ 20I40528I I I920I97950.html

9 Esperanza Aguirre esperanza.ppmadrid.es/el-populismo/ 
denominado partido post-crisis por García Agustín (20I5), quien lo ubica entre el populismo y el radicalismo.

La hipótesis de partida es que el lenguaje y el modo de tratamiento en el ámbito político español se ha ido volviendo más agresivo y violento desde hace unos años, con la aparición de los partidos emergentes Podemos y Ciudadanos como hito importante: "En España, con la nueva era política del cambio, nacen Ciudadanos y Podemos, que se presentan como regeneradores de una situación 'catastrófica"” (Alcaide Lara 2016, cursivas en el original). Sin embargo, el modo de dirigirse y de tratar la comunidad política, y también periodística, a uno y a otro partido no es similar: el partido de centro-derecha Ciudadanos y su líder Albert Rivera, con una imagen profesional atildada y cuidada, se presentan ideológicamente como una alternativa a la derecha del Partido Popular, desde el sistema, y no han sido objeto del descrédito basado en ataques personales. El partido post-crisis Podemos (García Agustín 20I 5), Pablo Iglesias y sus miembros, con sus ideas y actitudes anti-sistema, son vistos como rebeldes e irrespetuosos con las formas habituales en el mundo político ${ }^{\mathrm{IO}}$ y como un riesgo que, desde las posturas más encontradas, hay que desacreditar a toda costa, aun acudiendo al escarnio y la ridiculización ${ }^{\mathrm{II}}$.

Es necesario puntualizar que los debates políticos no están exentos, ni antes ni ahora, de comportamientos que en otra situación serían vistos como descorteses y que caen dentro de las expectativas de confrontación pertinentes en la situación discursiva (Blas Arroyo 2003, 2010). A modo de ejemplo, Blas Arroyo (2003) muestra la existencia de agresividad y descortesía en los debates entre Felipe González (PSOE) y José María Aznar (PP), ambos candidatos presidenciales en las elecciones de I993. Aznar acusó a González de faltar a la verdad: "Mire, vuelve usted y perdóneme que se lo diga, porque no se lo quiero decir con ningún ánimo agresivo, ni mucho menos ofensivo, señor González a faltar a la verdad..." (Blas Arroyo, 2003: 404). La acusación de mentir -faltar a la verdad- en un debate electoral no es ajena al objetivo del político de descalificar a su adversario con tal de quedar en mejor posición. Sin

Io http://www.lavanguardia.com/de-moda/moda/celebrities/20 I 4 I I 23/5442009 I 3 I 7 / pablo-iglesias-politico-coleta-que-arrasa-con-su-estilo.html

${ }^{11}$ Hecho del que, efectivamente, se hacen eco algunas publicaciones en clave de humor: http://viejuna.eljueves.es/20I4/05/30/rtve_vetara_aparicion_hombres_con_ coleta_perilla_todos_sus_programas.html. Podemos se considera objeto de una campaña de hostigamiento como lo denuncia en: http://podemos.info/prensa/ comunicado-de-podemos-sobre-la-noticia-de-el-pais/ 
embargo, esa acusación expresada con diferentes estrategias de atenuación contrasta con la acusación de Pedro Sánchez (PSOE) a Mariano Rajoy (PP) en un debate previo a las elecciones generales de diciembre de 201 5: "porque el presidente, señor Rajoy, tiene que ser una persona decente y usted no lo es" (con énfasis prosódico en 'usted' y señalando con el dedo a Rajoy); esto es, sin atenuación y atacando a la persona en lo que es un valor socioculturalmente de gran importancia en la sociedad española, la decencia (Bernal, e. p.).

\section{Unos apuntes sobre Podemos}

Podemos nació, desde posturas de la izquierda anticapitalista, como una fuerza de participación y empoderamiento ciudadanos, según informa el partido en su página web: "Podemos es un método para el protagonismo popular y ciudadano. Queremos que nuestro programa se conforme a través de la participación de la ciudadanía y los Círculos Podemos. Nadie sabe mejor qué es lo que necesitamos que los ciudadanos que día a día sacan adelante el país" (http://podemos.info/circulos/). Las raíces de Podemos se encuentran en las movilizaciones y protestas emprendidas el I 5 de mayo de 20 I I en Madrid, conocidas como el Movimiento del I 5-M $\mathrm{M}^{12}$, los indignados, como consecuencia de la crisis económica y las políticas de austeridad del partido en el Gobierno, Partido Popular, que plantearon el cuestionamiento del sistema bipartito de gobierno así como la protesta ante las desigualdades sociales y la corrupción (García Agustín 20 I 5). En este sentido, el nuevo discurso político de Podemos hizo uso de términos que resultaron de gran calado, como "la casta", para referirse a esa clase política -y corrupta- alejada de los deseos y necesidades del pueblo ${ }^{13}$.

La participación de los políticos de Podemos en diferentes medios de comunicación fue profusa en sus comienzos, incluso a través de programas de televisión de producción propia (La tuerka), además de acudir a diversos programas de debate y tertulias televisivas. Otro aspecto novedoso en un partido político español fue el hecho de recurrir a la financiación compartida (crowdfunding) como modo de afrontar

\footnotetext{
${ }^{12}$ Véase Pérez Vicente (20I3) para un análisis retórico del lenguaje utilizado en pancartas y carteles del I 5 -M.

${ }^{2}$ Para una caracterización del discurso populista, véase Charaudeau (2009), y, más concretamente sobre el discurso populista de Podemos, véase García Agustín (20 I 5 ) y Alcaide Lara (2016 y en este volumen).
} 
determinados gastos y facilitando, de este modo, que los simpatizantes del partido contribuyeran al proyecto común.

En cuanto al espectro ideológico, Podemos se ubica en el ala izquierda republicana y nace con el anhelo de convertirse en una alternativa fuerte frente a Izquierda Unida (partido liderado en la actualidad por Alberto Garzón). Como apunta Hernández Flores (20I4 y en este volumen), Pablo Iglesias, doctor en Ciencias Políticas y profesor universitario en sus inicios como líder de Podemos, construye su identidad política sobre la base de la asesoría en comunicación, y, aparte de su discurso externo hacia los políticos y la ciudadanía, elabora un discurso interno cuyo destinatario principal son sus compañeros de izquierdas:

para los cuales crea una serie de roles y de espacios que van desde un espacio ideológico tradicional y muy politizado donde estaría la vieja izquierda de grandes ideales que nunca llega a proclamarse victoriosa en contiendas electorales, y la izquierda igualmente cargada de ideología pero con un objetivo pragmático, que es el defendido por Iglesias: acercarse a un electorado mayoritario que no es de extrema izquierda, ni siquiera de izquierdas, pero al que, debido a un contexto de crisis política, social y económica, con la corrupción en primer plano, se puede acceder mediante las ideas de izquierdas. (Hernández Flores, en este volumen).

\section{Materiales y método}

Abordaremos en un análisis cualitativo las estrategias discursivas relativas a la configuración de la imagen de los políticos de Podemos en dos textos principales procedentes de políticos conservadores y que consisten en comentarios realizados por Celia Villalobos y por Esperanza Aguirre, miembros del Partido Popular:

a. Esperanza Aguirre (presidenta del Senado entre I999 y 2002, presidenta de la Comunidad de Madrid entre 2003 y 20I2, entre otros cargos políticos): columna de opinión publicada en el diario conservador $A B C$ y en su blog personal que contiene paralelismos entre Hitler e Iglesias/Podemos ( $\mathbb{S}$ 5.I; Apéndice I).

b. Celia Villalobos, vicepresidenta primera del Congreso de los Diputados desde 20I I hasta finalizar la XI Legislatura el 3 de mayo de 2016 (http://www.pp.es/celia-villalobos), comentarios sobre la higiene personal al referirse a las rastas (dreadlocks) de Alberto Rodríguez, diputado del partido Podemos: "que las lleven limpias y no me peguen los piojos” ( $\$$ 5.2; Apéndice 2 ). 
Concretamente, el análisis de los textos consiste en identificar la presencia de argumentos ad hominem y ad populum, como muestras de argumentos falaces, de carácter destructivo y mayormente relacionados con la descortesía (cf. $\mathbb{S}$ 3.I y 4.I), así como las actividades de imagen social (que pueden afectar, además de a la faceta personal, al rol profesional y social). Atenderemos también al efecto social del tratamiento de la imagen en los textos analizados y a su repercusión en diferentes planos. En este sentido, propone Bolívar (2005: 280), al estudiar los insultos en el discurso político venezolano, el uso del "macro-diálogo" y los "macro-intercambios", para describir los procesos discursivos involucrados en las prácticas políticas; así, metodológicamente, es posible abordar las acciones y las reacciones a ellas.

\section{Conceptos teóricos}

El discurso político, además del objetivo informativo, tiene, en palabras de Fernández Lagunilla (I999: 48), un carácter agitativo, ya que busca conseguir una reacción positiva en el destinatario haciendo que se adhiera al emisor en nombre de una idea o de una norma para el bien común. Según esta autora, las estrategias argumentativas principales son la seducción y la persuasión, que apelan, respectivamente, a la emoción -los sentimientos- y al intelecto del destinatario. En el contexto político, los fines estratégicos de la argumentación, indica Fuentes Rodríguez (20I I), son dos: realizar la tarea de oposición con respecto a los otros (el exogrupo) y crear una imagen "para vindicarse ante el endogrupo"; en este sentido, la descortesía resulta en los procesos de argumentación un mecanismo de uso estratégico.

Partiendo de la definición de estrategia discursiva como "el modo en el que las expresiones gestionan el discurso con una determinada finalidad comunicativa" (Bravo, 20 I 5: 58), integraremos las actividades propiamente argumentativas y las actividades de imagen, que se plasmarán en un análisis en dos niveles: temático y socioemocional (Bravo, 20 I 5: 7I). Ya Bravo (I999), analizando el transcurso de unas negociaciones, observó el uso de argumentos ad hominem como desaprobaciones personales, esto es, amenazas a la imagen social de los oponentes en un sentido tanto grupal como individual. Retomaremos estos aspectos a lo largo de este apartado.

Alcaide Lara (2014: 25I) plantea una relación biunívoca entre dos estrategias discursivas, la argumentación y la (des)cortesía, sin relación de subordinación a priori entre ambas. Esta autora aporta ejemplos del 
debate parlamentario donde la imagen personal del contrincante queda absolutamente afectada de modo negativo, legitimándose el acto descortés a través de los argumentos. En tipos de discurso marcadamente persuasivos, es la estructura argumentativa la que sirve para apoyar y legitimar la actividad descortés (Alcaide Lara 20I4), pudiéndose "utilizar estrategias (des)corteses para argumentar y, por ende, persuadir, o estructuras argumentativas para reforzar nuestras actividades de (des) cortesía. En cualquier caso, el fin último es la persuasión de nuestro destinatario." (cf. Halmari y Virtanen 2005).

\subsection{Discurso ideológico}

Para van Dijk (2003), las ideologías son las creencias fundamentales de un grupo y de sus miembros, que fundamentan sus prácticas sociales y que no incluyen las normas y valores socioculturales de un grupo (el "fundamento común"), ya que son creencias compartidas y no cuestionadas. Las ideologías "suelen generar diferencias de opinión, conflictos y luchas” (van Dijk, 2003: 23). El discurso ideológico responde a la siguiente estrategia básica (van Dijk, 2003: 57): "Hablar de Nuestros aspectos positivos / Hablar de Sus aspectos negativos". La presentación positiva propia y negativa del otro caracteriza el cuadrado ideológico, cuyos principios son aplicables al análisis de todas las estructuras del discurso (van Dijk, 2003: 58):

- Poner énfasis en Nuestros aspectos positivos.

- Poner énfasis en Sus aspectos negativos.

- Quitar énfasis de Nuestros aspectos negativos.

- Quitar énfasis de Sus aspectos positivos.

Para ello, el énfasis en los significados se hace mediante mecanismos léxicos y semánticos, el uso de determinadas estructuras proposicionales, la sintaxis, la argumentación (argumentos falaces) y las figuras retóricas. La dimensión social de todo discurso (van Dijk, 2003: 75) también debe ser considerada.

\subsection{Argumentos emocionales destructivos}

Las acusaciones desde el ataque a cualidades y valores personales constituyen el núcleo de la argumentación ad hominem, conectando estos argumentos falaces con la descortesía (Kienpointner 2008; Alcaide Lara 20I4). Las emociones se definen como procesos psicológicos experi- 
mentados como sentimientos fuertes, ya sean positivos como el amor y el afecto, o negativos como el odio y el miedo (Kienpointner, 2008: 246). Respecto a los argumentos falaces, indica este autor que son movimientos argumentativos no cooperativos ya que "fallacies block the general goal of finding a joint resolution to a conflict of opinion by reasoning" (Kienpointner, 2008: 247) e indica que no todos los argumentos emocionales son falaces: ya Aristóteles reconocía las emociones -pathos-como modo legítimo de persuasión.

En lo que atañe a la descortesía, especialmente los argumentos ad hominem (ataques personales que cuestionan las capacidades físicas y mentales, combinados con insultos y términos despectivos; acusaciones de parcialidad inherente y permanente ${ }^{\mathrm{I} 4}$; reproches sobre la pertenencia a un grupo social que, según el hablante, tiene características negativas) y los argumentos ad populum (acudir a lo que la mayoría o un determinado grupo piensa) tienden a ser falaces y groseros. Kienpointner (2008: 249) llama "destructive" emotional arguments a los argumentos que son falaces y descorteses, en los que las estrategias de descortesía son usadas para agravar el impacto de los argumentos falaces al amenazar la imagen social de los oponentes.

A modo de ejemplo, observemos una muestra de comentarios que se inmiscuyen en la esfera privada, el aspecto físico y el aseo personal de Pablo Iglesias, que aparece en el siguiente extracto de una columna de opinión publicada en el diario La Razón (cf. Bernal 2016):

\section{Alfonso Ussía (periodista). El Coletas. I2 agosto 20I4. larazon.es ${ }^{15}$}

Ya eurodiputado, lo primero que tendría que hacer el Coletas es frecuentar más su lavado. El lavado de las coletas, su signo de identidad, símbolo piloso de los indignados, si bien su indignación ha tenido que menguar en estos últimos meses, tan productivos en la recepción de los emolumentos tertulianos de las cadenas de televisión capitalistas. Nada tiene que ver el comunismo radical y estalinismo orgánico con el champú. Si no desea adquirirlo en comercio del ramo, puede perfectamente solicitarlo en los salones de maquillaje y peluquería de la Cuatro y de La Sexta, sus cadenas de televisión preferidas y a las que debe su éxito en las elecciones al Parlamento europeo. No obstante, y para dar ejemplo a sus compañeros de grupo, entre los que destaca el futurible Jiménez-Villarejo, haría

${ }^{{ }^{14}}$ Kienpointner (2008: 253) aporta un ejemplo en que se acusa al oponente de mentiroso diciendo que su principal lealtad no es para con la verdad ("Cardinal Newman's claims were not to be trusted because, as a Roman Catholic Priest, (Kingsley alleged) Newman's firs loyalty was not the truth".

${ }^{15}$ http://www.larazon.es/opinion/columnistas/el-coletas-GD6489 I I 8 
bien en adquirirlo en un supermercado, porque I7.000 euros mensuales no dan para mucho, pero sí para un buen lote de champú, incluso de champú importado, de champú francés, que dejaría más ligeras, volanderas y leonas sus preciosas coletillas. [...] Al menos, que las lleve lavadas, aseadas, lacadas y acariciables.

En este pasaje se critican, temáticamente, varios aspectos:

- Iglesias no ha sido consecuente con el mensaje del movimiento del I $5 \mathrm{M}$ ("su indignación ha tenido que menguar"), creando la implicatura de que su compromiso con los indignados ha disminuido.

- Iglesias cobra por participar en los debates televisivos; comulga así con las grandes cadenas de televisión y con el capitalismo ("la recepción de los emolumentos tertulianos de las cadenas de televisión capitalistas"), constituyendo ello una contradicción respecto a los ideales anticapitalistas que maneja el partido.

- El éxito en las elecciones al Parlamento Europeo de debe a la profusión en debates y programas de televisión ("la Cuatro y de La Sexta, sus cadenas de televisión preferidas y a las que debe su éxito en las elecciones al Parlamento europeo"), no a sus ideas políticas.

- El sueldo de Iglesias como parlamentario europeo es muy alto, I 7.000 euros; no podemos dilucidar si se trata de una errata o que el autor ha escrito adrede una cifra que casi multiplica por diez la retribución que le corresponde como eurodiputado.

El aspecto que permea todo el texto es la argumentación ad hominem: las alusiones al aseo personal de Pablo Iglesias, o, más bien, a la falta de aseo ("frecuentar más su lavado", "un buen lote de champú”, "sus preciosas coletillas", "que las lleve lavadas, aseadas...”), lo cual corresponde a una estrategia de ataque basada en la desacreditación de las cualidades personales en relación al aspecto físico, esto es, sobrepasa lo meramente ideológico y político, ya que marca a la persona como sucia y -por extensión- como poco deseable socialmente.

Un aspecto destacado en los estudios sociopragmáticos es la necesidad de atender al efecto social que producen los comportamientos comunicativos en general y las posibles amenazas a la imagen social en particular. Según Bravo (201 5: 52), "los efectos sociales de las actividades de imagen dependen del posicionamiento relativo de auditorios presentes y virtuales en relación a la disputa entre dos tesis antagónicas”, esto es, además de las partes involucradas en el evento comunicativo 
también otros auditorios virtuales interpretan significados extradiscursivos relacionados con las actividades de imagen.

Dado el carácter del discurso que nos ocupa, un modo de incorporar al análisis cuál es la interpretación por parte de esos auditorios virtuales es realizar una consultación espontánea (Kaul de Marlangeon 20I5; Bernal 20I6) a través de los foros donde, a continuación de la noticia, columna de opinión u otros textos expuestos en los diarios digitales, se manifiestan los lectores. Así podemos observar que en la columna de opinión anterior se registraron i 86 comentarios el mismo día de su publicación, el I 2 de agosto de $20 \mathrm{I} 4^{16}$; en este caso, los lectores (el alias se muestra entre paréntesis al principio del ejemplo, presentado literalmente) recalcan el carácter maleducado y el escarnio:

- (Lola). Que cosa mas maleducada el ussia. Y tanto periodista preparado en paro...Que Pena...

- (Tristam Shandy). Esa lengua con aliento a orinal de Ussía destila mucho odio, impotencia y rabia. Y ya se sabe, que cuando uno contesta con tanta acritud es porque se siente agredido. Hasta ahí llega el triunfo del coletas, que sin él dirigirse a él, tiene Ussía que rebajarse al escarnio propio de un patio de instituto. No sólo ha quedado bien retratado, encima ha hecho válida la frase de Diogénes de Sínope que dice que el insulto deshonra a quien lo infiere, no a quien lo recibe. $\mathrm{Y}$ al haber recurrido al ad hominem, encima admites que su programa político es invatible [sic] y que por eso no te atreves a atacarlo. Tanto libro leído para esto, Ussía.

\subsection{Imagen social y descortesía por fustigación}

La noción de imagen básica, desarrollada por Bravo (I999), se refiere a la imagen sociocultural reconocida por los miembros de un determinado grupo social, por ejemplo, el ideal de sinceridad en las sociedades mediterráneas. La imagen social básica tiene, según esta autora, dos vertientes: por un lado, la imagen de autonomía respecto a lo que dis-

${ }^{16}$ En una consulta realizada a la misma página el Io de octubre de 2017 se observa un solo comentario: "Vaya falta de respeto... A lo de Pablo Iglesias dicen muchos que no se le puede llamar política, pero... ¿̇a esto se le puede llamar periodismo? Góngora y Quevedo eran más sutiles y originales. Aquí no cabe la sátira cuando hay tanta parcialidad.” http://www.larazon.es/opinion/columnistas/el-coletas-GD6489 I I 8: NosoyJulioIglesiassoymileuri 
tingue al individuo del grupo, y, por otro lado, la imagen de afiliación, respecto a los deseos de identificación con el grupo (cf. Bravo, 2003: I06). En la dialéctica individuo-grupo, los contenidos concretos de estas imágenes dependen de los contenidos socioculturales compartidos en la sociedad en cuestión. En la sociedad española, algunos contenidos de la configuración de la imagen de autonomía serían la expresión de autoafirmación y autoestima "el ser original y consciente de las buenas cualidades propias” (Bravo, I999: I68), y, para la imagen de afiliación, las muestras de afecto y confianza, entendiendo la confianza como familiaridad e intimidad.

En un contexto profesional como es el político es importante también la noción de imagen de rol (Bravo, 2004: 29) cuyos contenidos se plasman según los diferentes roles desempeñados cotidianamente. Tanto la imagen básica como la imagen de rol vienen definidas social, cultural y situacionalmente (Bravo I999).

Relacionando las actividades de imagen con la descortesía, Kaul de Marlangeon (2005) apunta tanto a la afiliación exacerbada al grupo como a la refractariedad (una autonomía exacerbada, que también acude a la descortesía), que se concretan en una descortesía de fustigación a través de recursos como el reproche in crescendo, la corrección sin suavizadores, el comentario descalificador, el zaherimiento, la tergiversación, la estrategia de situarse en el papel de víctima, de burla y de insulto, los vocativos lesivos de imagen y la escalada descortés.

En la dinámica entre grupos, Kienpointner (I997: 27I) denominó descortesía inter-grupal (inter-group rudeness) a las estrategias descorteses del grupo mayoritario (in-group, o endogrupo) para degradar a los miembros de otros grupos (out-groups, o exogrupo). En el macro-diálogo político, apunta Bolívar (2005: 280) de acuerdo con Chilton y Schäffner (2000: 304-306), la descortesía merece una atención especial porque "tiene un valor ideológico y puede usarse con diferentes funciones estratégicas en la interacción política, tales como la coerción, la resistencia, la oposición y la protesta, el encubrimiento, la legitimación y la deslegitimación" (cursivas en el original).

\section{Análisis}

Procedemos a continuación al análisis de las dos situaciones elegidas, en las que incluimos su repercusión en varios niveles de alcance, presentándolas, por lo tanto, como macro-intercambios: 


\subsection{Macro-intercambio 1: Esperanza Aguirre (PP)}

A) Texto de Esperanza Aguirre. El populismo - Blog Esperanza Aguirre esperanza.ppmadrid.es/el-populismo/

El texto (cf. Apéndice) que nos ocupa apareció publicado en el blog de Esperanza Aguirre, entonces presidenta del Partido Popular de la Comunidad de Madrid, y también como columna de opinión en el diario $A B C$, de orientación política conservadora. El texto va acompañado de una ilustración donde se muestra una figura de hombre que pretende representar a Pablo Iglesias, con perilla y coleta, vestido con camisa blanca, corbata anudada informalmente y pose desenfadada, con las manos en los bolsillos. Tanto la cara de la figura como el círculo que es el logotipo del partido Podemos, aparecen en blanco. Consideramos que esta imagen funciona como paratexto visual que añade información al texto (Bravo e. p.): Iglesias y Podemos se muestran como vacíos de contenido y como alternativa política inexistente.

El impacto persuasivo de asemejar a Podemos con los nazis y los comunistas (Goebbels y Wützenberger, "genios de la maldad") que realiza Aguirre responde al argumento mencionado por Kienpointner (2008: 256): "As guilt by association ad hominem attacks rely on the membership of a person within ethnic, social or political group for their persuasive impact". En este caso, Aguirre apela a las emociones negativas de los lectores frente a ciertos grupos afirmando que Ellos (Podemos) son diferentes de Nosotros: los políticos del PP, los demócratas, los partidarios del bipartidismo, los políticos "de toda la vida", respecto a los cuales, en cualquier caso, Podemos constituiría el polo opuesto. Si pensamos en el cuadrado ideológico de van Dijk (2003) (cf. $\$ 4 . I$ ), se pueden observar en la Tabla I las siguientes estrategias para "hablar de Nuestros aspectos positivos" y "Hablar de Sus aspectos negativos":

Así, en los contenidos bajo "Quitar énfasis de Sus aspectos positivos”, lo que podría ser considerado positivo (tener éxito, conseguir adeptos, mostrar pasión) es revertido a circunstancias negativas: la gente que los cree lo hace de mala fe, el uso exitoso de la propaganda se debe a prácticas nazis, la intensidad se iguala a maldad.

La repercusión de esta columna de opinión se puede observar en varios niveles, que mostramos a continuación, como parte del "macrointercambio": 
Tabla 1. Análisis según los conceptos del "cuadrado ideológico" (van Dijk 2003). Copyright: María Bernal. Licencia: CC BY

Poner énfasis en Nuestros aspectos positivos

- hemos aprendido de la historia

- sabemos de los peligros de este tipo de movimientos

- no creemos que los argumentos simplistas y falaces se descalifiquen solos

- sabemos que sus argumentos han sido desprestigiados por la historia

- no reaccionamos de modo irresponsable

- no nos da pereza debatir

- sabemos que el comunismo solo trae crimen y miseria

- seguimos los cauces democráticos

- no nos cansamos de discutir (rebatir) los argumentos mentirosos

- amamos la libertad y conocemos los peligros de la demagogia populista

- creemos en la Constitución, como garante de nuestros derechos

\section{Quitar énfasis de Nuestros} aspectos negativos

Circunstancias que exceden al partido, son ajenas:

- crisis económica profunda, paro

- desconfianza de la gente hacia los partidos tradicionales

- 'menor' intensidad apasionada, pero que hay que superar
Poner énfasis en Sus aspectos negativos

- desprecian y vituperan a los partidos existentes

- se presentan como los salvadores de la patria, con soluciones simplistas

- todo lo que dicen los populistas es mentira

- sus argumentos son falaces y demagógicos

- no son partidos nuevos

- representan tradiciones antiguas y fracasadas

- nunca solucionan los problemas, en ningún sitio

- conocen muy bien las técnicas de propaganda del nazismo y del comunismo (implicatura: siguen esas pautas)

- si tienen éxito es por el uso adecuado de la propaganda

- Iglesias usa argumentos falaces en la cuestión de ETA; usa argumentos etarras

- desprecia la Constitución ("papelito"); desprecia a los partidos democráticos

- no siguen los cauces democráticos

Quitar énfasis de Sus aspectos positivos

- pueden conseguir que alguna gente los crea, aunque sea "de buena fe"

- pueden tener mucho éxito (si usan hábilmente la propaganda //paralelismo inmediato con Hitler)

- quienes muestran una apasionada intensidad son los peores 
B) Acciones legales de Podemos.

Podemos, sintiéndose objeto de una campaña de hostigamiento y difamación, inició acciones legales contra Esperanza Aguirre por vincular al partido con la banda terrorista ETA y contra el director del diario El Mundo, Eduardo Inda, por acusarle de financiación ilegal proveniente del régimen chavista de Venezuela ${ }^{17}$. Para afrontar las costas del proceso, acudió a la ayuda económica de los simpatizantes del partido mediante crowdfunding ${ }^{18}$, recabando una cantidad muy superior al objetivo ( I69\% Conseguido, I6.96 I €, Recaudado). El partido emitió comunicados en la prensa y colgó la información en su página web ${ }^{19}$.

La denuncia contra Aguirre fue desestimada (resolución de 3 de junio de 20I 5 ):

El País: 29/07/201 5. La Audiencia rechaza la demanda de Podemos contra Aguirre

Los magistrados consideran que las palabras de la presidenta del PP, que vinculó a la formación de Pablo de Iglesias con ETA y el chavismo, fueron dichas en un "contexto político"

C) Respuesta de Iglesias.

Por otro lado, Iglesias respondió a Esperanza Aguirre en los medios al comentario de afinidad con Goebbels: "el aliado de Goebbels fue Franco, el 'padre político del PP'”

MADRID, i6 Jul. (EUROPA PRESS) ${ }^{20}$ - El líder de Podemos, Pablo Iglesias, ha respondido este miércoles a la presidenta del PP de Madrid, Esperanza Aguirre, diciéndole que "si de alguien era aliado Goebbels era del gobierno español de Franco", al que ha calificado de "padre político de Aguirre y del PP". En una entrevista en Cuatro recogida por Europa Press, Iglesias ha respondido así a las palabras de Aguirre, que ha dicho que Podemos ha aplicado las "técnicas de propaganda" de los "genios de la maldad", en referencia a los propagandistas del comunismo y el fascismo. El eurodiputado ha recordado que Franco envió a la División Azul a pelear junto a los

${ }^{17}$ Ya en 2017 Iglesias perdió el juicio porque la juez encontró veraz y contrastada la acusación. https://okdiario.com/espana/20I7/04/I8/iglesias-pierde-juicio-indanoticia-cuenta-banco-offshore-veraz-920I4 I

I8 "Para poder financiarnos sin depender de los bancos ni de los poderes económicos, apostamos desde el inicio por desarrollar herramientas de financiación innovadoras y participativas inspiradas en los valores de la economía colaborativa, de manera que proponemos que la ciudadanía sea copartícipe de la financiación de los proyectos. Estas herramientas son las colaboraciones, los crowdfundings y los microcréditos (https://podemos.info/financiacion/)

$19 \mathrm{http}: / /$ podemos.info/prensa/comunicado-de-podemos-sobre-la-noticia-de-el-pais/

${ }^{20} \mathrm{http}: / / \mathrm{www} . e u r o p a p r e s s . e s / \mathrm{madrid} /$ noticia-iglesias-responde-aguirre-aliado-goebbels-fue-franco-padre-politico-pp-20I407 I6I 42442.html 
nazis en la Segunda Guerra Mundial y ha reprochado a Aguirre que nunca haya "condenado ni renegado del Franquismo". Iglesias achaca las críticas de Aguirre al "miedo de la casta porque se les acaba el chollo".

Las reacciones fueron amplias en las redes sociales, tanto a favor como en contra de Iglesias y de Aguirre, contribuyendo a la polarización de las opiniones y posturas.

En el nivel socioemocional, y respecto a la imagen social de grupo involucrada en estos intercambios, predomina la que afecta al desempeño del rol profesional -político, en este caso- tanto individual como del grupo (cf. Bravo 20 5: 64). En este sentido, cada uno cumple con la imagen de afiliación de grupo respecto a su partido, reafirmando las características de su grupo como tal. En los contenidos de autonomía de grupo, las características que identifican al propio grupo -el propio partido- frente al otro se observan en la Tabla 2:

Tabla 2. Contenidos de la imagen social de grupo. Copyright: María Bernal. Licencia: CC BY

\begin{tabular}{lll}
\hline $\begin{array}{l}\text { Imagen involucrada: } \\
\text { Autonomía de grupo }\end{array}$ & Aguirre/PP & Iglesias/Podemos \\
\hline Imagen de autono- & • Aguirre y & - descrédito como político/s: \\
mía en cuanto al rol & su partido & mentirosos, falaces, \\
situacional político & son políticos & demagógicos, no respetan \\
$\rightarrow$ Aguirre/PP hacia & reputados, & la Constitución, incapaces \\
Iglesias/Podemos & defensores de la & de aportar soluciones, \\
& verdad, garantes & afinidades peligrosas para \\
& de la democracia & la sociedad (terrorismo \\
& y, por ende, de los & etarra), desprecian los \\
& derechos humanos & cauces democráticos y, \\
& & por ende, no respetan los \\
& & derechos humanos \\
Imagen de autono- & Aguirre y el PP & - Aguirre y el PP se \\
mía en cuanto al rol & son franquistas & desmarcan de cualquier \\
situacional político & y nunca han & pasado franquista o de \\
$\rightarrow$ Iglesias/Podemos & renegado de ese & afinidad al nazismo \\
hacia Aguirre/PP & pasado franquista & - son una alternativa válida \\
& Franco apoyó a & que va a cambiar las cosas \\
& Hitler con el envío & (“a la casta se les acaba el \\
& de la División azul & chollo") \\
& tienen miedo de & son consecuentes con sus \\
& Podemos & ideas y emprenden acciones \\
& & legales para defenderse \\
\hline & &
\end{tabular}




\subsection{Macro-intercambio 2: Celia Villalobos (PP)}

Como mencionamos anteriormente, el ataque a la imagen personal de Pablo Iglesias y otros diputados de Podemos, señalando un descuido de la apariencia física y la higiene, fue muy frecuente en los inicios de Podemos como partido político pero siguieron prolongándose en el tiempo. El ataque ad hominem fue realizado también por Celia Villalobos, con una larga carrera política dentro de las filas del PP y vicepresidenta primera del Congreso de los Diputados desde 20II hasta mayo de 20I6, hacia el diputado de Podemos por Santa Cruz de Tenerife, Alberto Rodríguez, durante la sesión constitutiva de la XI Legislatura de las Cortes Generales el I 3 de enero de 2016.

\section{A) Comentarios de Celia Villalobos}

Celia Villalobos, en una tertulia del programa La Mañana (Televisión Española), se expresó sobre el diputado Alberto Rodríguez, que llevaba rastas, de la siguiente manera: "Que las lleven limpias y no me peguen piojos" ${ }^{21}$.

El País: Celia Villalobos: "No me importan las rastas, pero limpias y sin piojos” ${ }_{22}$

"A mí que un diputado de Podemos, o que fuera del PP o de donde fuera, lleve rastas, pues yo tengo sobrinos y familiares y chavales que llevan rastas, a mí con que las lleven limpias, para que no me peguen un piojo, me parece perfecto", ha dicho en una entrevista en el programa La Mañana de TVE. Ante la polémica desatada por sus palabras, la vicepresidenta ha vuelto a comentar el tema horas más tarde para defenderse: "tengo en mi familia chicos jóvenes que llevan rastas bastante más largas que este diputado".

Si bien Villalobos aparenta tolerancia, al decir que a ella no le importa que los diputados lleven rastas, actualiza la idea de poca higiene no solo de la persona concreta (Alberto Rodríguez), sino que también lo hace extensivo a todos los que llevan rastas con el uso del plural (lleven, peguen). Consideramos que es un caso evidente de ridiculización a través de argumentos ad hominem (Kienpointner 2008) y de descortesía de fustigación (Kaul de Marlangeon 2005), usada estratégicamente por Villalobos -incluso se apoya en su propia familia para justificar la

${ }^{21}$ http://www.vozpopuli.com/actualidad/nacional/Celia_Villalobos-CongresosPodemos-Rastas-Alberto_Rodriguez-Congreso-PP-diputados-rastas_o_8804 I I 954 . html

${ }^{22}$ https://politica.elpais.com/politica/20I 6/oI/I 4/actualidad/I4 527847 I 4_645 528. html 
descortesía- como descrédito y desmerecimiento profesional del adversario: no solo su imagen personal queda afectada sino que su imagen de rol como político queda también en entredicho (alguien que no sabe comportarse con unos mínimos criterios aceptados en la sociedad, puede quedar cuestionado para desempeñar un rol público).

Pensamos que aquí la estrategia básica, siguiendo a van Dijk (2003), es la presentación positiva propia y negativa del otro en los siguientes términos:

Tabla 3. Presentación de la imagen según los conceptos del cuadrado ideológico (van Dijk 2003). Copyright: María Bernal. Licencia: CC BY

\begin{tabular}{lc}
\hline $\begin{array}{l}\text { Hablar de Nuestros aspectos } \\
\text { positivos }\end{array}$ & Hablar de Sus aspectos negativos \\
\hline - tolerante y abierta & $\bullet$ ser sucio, poco deseable \\
- por implicatura: yo sí soy limpia & socialmente \\
$\begin{array}{l}\text { y no tengo piojos, soy respetuosa } \\
\text { con el decoro que exige el cargo } \\
\text { público }\end{array}$ & por extensión, poco adecuado \\
\hline
\end{tabular}

B) Eco en la prensa

Las palabras de Villalobos fueron ampliamente recogidas por los medios de comunicación; a modo de ejemplo, entre otros en $A B C^{23}, E l M u n d o^{24}$, El País ${ }^{25}$, La Vanguardia ${ }^{26}$. Hubo numerosas reacciones en las redes sociales, siendo uno de los temas más comentados en Twitter. Algunos políticos de Podemos se expresaron así (El País, I 8 enero 20I6):

- Miguel Ardanuy (diputado de Podemos en la Comunidad de Madrid): "Ojalá el partido de Celia Villalobos estuviera la mitad de limpio que mis rastas".

- Rita Maestre (Ahora Madrid/Podemos, portavoz del Ayuntamiento de Madrid): a Celia Villalobos se le debería presuponer buena

${ }^{23} \mathrm{http} / /$ www.abc.es/espana/abci-villalobos-no-importa-diputados-podemos-llevenrastas-siempre-esten-limpias-20I60I I4I34 I_noticia.html

${ }_{24} \mathrm{http} / /$ www.elmundo.es/espana/20I6/oI/I 4/56978fc446 I 63 fc7298b45ca.html

${ }_{25} \mathrm{http}: / /$ politica.elpais.com/politica/20I6/oI/I 4/actualidad/I4527847I4_645528.html

${ }^{26} \mathrm{http}: / / \mathrm{www}$.lavanguardia.com/politica/20 I 60 I I 4/30 I $399358568 /$ celia-villa lobos-rastas-piojos.html 
educación como a cualquier cargo público que hable en representación de los ciudadanos.

- Íñigo Errejón (Podemos): "lo que lastra la higiene de un grupo parlamentario es la corrupción”.

Algunos comentarios recogidos por los medios de comunicación por parte de políticos del PP y periodistas afines a su ideología van en una línea diferente, desde insistir en el argumento ad hominem hasta quitarle importancia achacándolo a una broma:

- Pilar Cernuda, periodista conservadora, tertulia de la cadena de televisión Antena 3 Espejo Público: "Un poquito de limpieza, que en el hemiciclo conviven muchas personas juntas". "Digo lo que vi y lo que olí. Hace falta limpieza, que sí. La progresía no está reñida con el baño ni con la ducha" ${ }^{27}$.

- Rafael Hernando, portavoz del Grupo Popular en el Congreso: "es una forma simpática de hablar, no tiene más trascendencia" ${ }^{28}$.

C) Reacción de Alberto Rodríguez

Alberto Rodríguez se expresó así en su cuenta de Twitter²9: “A pesar de sus abucheos, gritos e insultos, no consiguieron callar las voces del cambio. Es imparable y lo saben". Otros comentarios suyos en la prensa han sido que los políticos de Podemos "eran foco de atención por ser precisamente eso, diversos y plurales, como la sociedad a la que representan" y culpa al "circo político-mediático" de la polémica provocada por sus $\operatorname{rastas}^{30}$. Dijo también que no le interesaba ese debate: "hay mucha gente en este país que lo está pasando muy mal, que necesita medidas urgentes, y en eso nos queremos centrar". Su estrategia argumentativa es abundar en la diferencia de Podemos respecto a los partidos tradicionales y presentar una imagen de partido preocupado por las cuestiones realmente importantes.

Concluimos este breve análisis con los aspectos socioemocionales relacionados con la imagen de grupo (el partido propio, endogrupo,

$27 \mathrm{http}: / /$ www.elmundo.es/espana/20I6/OI/I 4/56978fc446I63fc7298b45ca.html

${ }^{28} \mathrm{http}: / /$ www.malagahoy.es/malaga/Celia-Villalobos-rastas-limpias-piojos_ o_99020I684.html

http://www.abc.es/espana/abci-alberto-rodriguez-diputado-lucha-clases-entre-rastas20I60II50745_noticia.html

29 Alberto Rodríguez@Alber_Canarias

${ }^{30}$ https://politica.elpais.com/politica/20I6/oI/I 5/actualidad/I452875642_240852.html 
frente al partido adversario, exogrupo). Como en el macro-intercambio anterior, las actividades de afiliación para con el propio grupo se puede observar en los dos partidos. Observamos en la Tabla 4 las actividades relacionadas con la imagen de autonomía:

Tabla 4. Contenidos de la imagen social de grupo. Copyright: María Bernal. Licencia: CC BY

\begin{tabular}{lll}
\hline $\begin{array}{l}\text { Imagen involucrada: } \\
\text { Autonomía de grupo }\end{array}$ & Villalobos/PP & Rodríguez/Podemos \\
\hline Imagen de autono- & • ella y su partido son & $\bullet$ son sucios \\
mía en cuanto al rol & limpios, respetuosos con & $\bullet$ irrespetuosos con las \\
situacional político & las formas y el decoro & formas \\
$\rightarrow$ Villalobos/PP & - ella es tolerante & $\bullet$ poco aptos para \\
hacia Rodríguez/ & - no hay ataques sino & ejercer cargos \\
Podemos & una forma simpática de & públicos \\
& hablar (broma) & \\
Imagen de autono- & el PP es un partido & $\bullet$ se interesan por los \\
mía en cuanto al rol & sucio, la suciedad reside & problemas reales de \\
situacional político & en la corrupción & la gente \\
$\rightarrow$ Rodríguez/ & Villalobos no tiene & $\bullet$ representan la \\
Podemos hacia & buena educación, no es & diversidad que hay \\
Villalobos/PP & apta para representar a & entre los ciudadanos \\
& los ciudadanos & $\bullet$ por implicatura, ellos \\
& quieren acallar las voces & no son corruptos \\
& del cambio, se centran & como el PP \\
& en nimiedades, no en los & $\bullet$ son la alternativa del \\
& problemas de la gente & cambio \\
\hline
\end{tabular}

Consideramos que, si hace unos años un político -José Bono, entonces Presidente del Congreso- le afeaba a otro político que no llevara corbata $^{3 \mathrm{I}}$, la escalada hasta tildar de sucio a un adversario político es patente.

\section{Conclusiones}

En este trabajo nos hemos propuesto profundizar en el estudio de las estrategias discursivas de descalificación del adversario político, para

\footnotetext{
${ }^{31}$ http://www.2ominutos.es/noticia/I I I 553 8/o/corbata/miguel-sebastian/jose-bono/
} 
lo que hemos considerado las actividades de imagen como estrategias argumentativo-discursivas (Bravo 2015), los argumentos falaces de corte emocional, argumentos ad hominem (Kienpointner 2008), y hemos atendido a las características del discurso ideológico (van Dijk 2003). Concretamente, nos hemos centrado en actividades de ataque a la imagen personal de Pablo Iglesias y de otros integrantes del partido Podemos como muestra de una descortesía de fustigación (Kaul de Marlangeon 2005) basada en insultos (Bolívar 2005).

La hipótesis de partida es que, en los últimos años, en el ámbito político español se ha recrudecido el lenguaje volviéndose más agresivo y violento; pensamos que a ello ha contribuido la aparición de Podemos como partido post-crisis enfrentado a los valores de los partidos políticos tradicionales. Hemos analizado muestras de diferentes discursos de la escena mediática (Charaudeau 2005), como columnas de opinión, comentarios realizados en debates televisivos, etc., con el objetivo de observar algunas estrategias que suponen una suerte de demonización de Podemos y sus miembros y que persiguen su descrédito político. Hemos mostrado, sobre todo por parte de políticos y periodistas de orientación ideológica conservadora, algunas amenazas orientadas a la imagen del político/de los políticos de Podemos, no solo en lo concerniente a la ideología política y actuación conforme a ella, sino que hacen una descalificación personal inmiscuyéndose en la esfera privada, su aspecto físico y su aseo personal.

Nos ha parecido relevante también mostrar repercusiones y consecuencias para reflejar mejor la dialéctica en torno a las situaciones bajo análisis (macro-intercambios); especialmente, el caso de la descortesía se puede considerar en gran medida como una cadena de actos de carácter dialógico: a un insulto o comportamiento descortés le sigue una reacción. En nuestro análisis hemos mostrado la reacción de Podemos a los insultos; en un trabajo de mayor alcance sería pertinente abordar también si los insultos desde posiciones conservadoras pueden responder a un uso agresivo y sexista del lenguaje por parte de Pablo Iglesias (por ejemplo, al llamar "la menina" a la vicepresidenta del Gobierno entre 20I I y 20I8, Soraya Sáenz de Santamaría). La difusión de las noticias, los comentarios y foros en las nuevas redes sociales, y en otros contextos mediáticos hacen que se propicien y agudicen las afinidades políticas. Este trabajo es una contribución modesta que necesitaría de más estudios para profundizar en la imbricación entre argumentación y descortesía en el campo político. 


\section{Referencias}

Alcaide Lara, E. (20I4). "La relación argumentación-(des)cortesía en el discurso persuasivo." Sociocultural Pragmatics. An International Journal of Spanish Linguistics. Volume 2, Issue 2, 223-26I. https://doi.org/IO.I5I $5 /$ soprag-20I4-0008

Alcaide Lara, E. (2016). "Discursos populistas en la política española actual: el caso de Podemos y Ciudadanos". Workshop Political discourse in romance speaking countries: linguistic and social science perspectives (ROMPOL II), 9-I I/ıo/20I6. Universidad de Estocolmo.

Bernal, M. (2014). "'Lo primero que tendría que hacer el Coletas es frecuentar más su lavado'. Ridiculización y fustigación como posicionamiento en los medios ante la imagen de Pablo Iglesias, líder de Podemos". Workshop Political discourse in romance speaking countries: linguistic and social science perspectives (ROMPOL I), I9-2I/IO/20I4. Universidad de Estocolmo.

Bernal, M. (2016). "Actividades de imagen respecto al tema de la corrupción en una interacción entre Iglesias (Podemos) y Villalobos (PP)". En Dumitrescu, D. \& Bravo, D. (eds.), Roles situacionales, interculturalidad y multiculturalidad en encuentros en español, I 5 5-I78. Buenos Aires - Estocolmo: Dunken.

Bernal, M. (forthc., 2019). "Yo creo que ese día me equivoqué”. ¿Atenuación o reafirmación en el discurso de los políticos españoles?” Sociocultural Pragmatics. An International Journal of Spanish Linguistics.

Blas Arroyo, J. L. (2003). "'Perdóneme que se lo diga, pero vuelve usted a faltar a la verdad, señor González': form and function of politic verbal behaviour in face-to-face Spanish political debates”. Discourse \& Society I 4:4, 395-424.

Blas Arroyo, J. L. (2010). "La descortesía en contextos de telerrealidad mediática. Análisis de un corpus español”. En Orletti, F. \& Mariottini, L. (eds.), Descortesía en español. Espacios teóricos y metodológicos para su estudio (2010). Universidad Roma Tre - Programa EDICE, I 83-208.

Bolívar, A. (2005). "Descortesía y confrontación política”. En Bravo, D. (ed.), Estudios de la (des) cortesía en español. Categorías conceptuales y aplicacionea a corpora orales y escritos (273-297). Buenos Aires - Estocolmo: Dunken.

Bolívar, A. (2008). "Cachorro del imperio" versus "cachorro de Fidel": los insultos en la política latinoamericana. Discurso y Sociedad 2(I) I-38. www.dissoc.org

Bravo, D. (I999). “'Imagen "positiva” vs. imagen "negativa”? Pragmática socio-cultural y componentes de face." Oralia, 2, I $55^{-1} 84$. 
Bravo, D. (201 5). "Pragmática sociocultural para el análisis social del discurso. Actividades de imagen como estrategias argumentativo-discursivas en situación de testimonio judicial”. En Bravo, D. y Bernal, M. (eds.), Perspectivas sociopragmáticas y socioculturales del análisis del discurso (pp. 49-90). Programa EDICE. Buenos Aires: Dunken.

Bravo, D. (2016). “Aplicaciones de la Pragmática Sociocultural. Actividades de imagen y expresiones de subjetividad en una entrevista de la BBC de Londres al presidente de Ecuador, Rafael Correa". En Dumitrescu, D. \& Bravo, D. (eds.), Roles situacionales, interculturalidad y multiculturalidad en encuentros en español (pp. I I I-I4I). Programa EDICE. Buenos Aires: Dunken.

Bravo, D. (forth.). "Actividades de imagen como estrategias argumentativo-discursivas en textos de prensa en Argentina”. III Simposium Internacional EDiSo. Desigualdad y nuevos discursos sociales. 28-30/06/201 7, Universitat Pompeu Fabra, Barcelona.

Chilton, P. y Schäffner, C. (2000). "Discurso y política”. En van Dijk, T. (ed.), El discurso como interacción social. Estudios sobre el discurso II. Una introducción miltidisciplinaria, 297-329. Barcelona: Gedisa.

Consejo de Investigaciones Sociológicas (20I4). Avance de resultados del estudio 3033 Barómetro de Julio de 20 I4. Recuperado el I 4/08/20I4 de: http:// www.cis.es/cis/export/sites/default/-Archivos/Indicadores/Informes/20I4/ InformeIndicadoresJulio2o I 4.pdf

Consejo de Investigaciones Sociológicas (20I 7). http:/www.cis.es/cis/opencms/ ES/index.html

Charaudeau, P. (2005). Le discours politique. Les masques du pouvoir. Paris: Vuibert.

Charaudeau, P. (2009). Reflexiones para el análisis del discurso populista. Discurso y Sociedad 3(2): 253-279. http://www.dissoc.org/ediciones/ vo3no2/DS $3(2)$ Charaudeau.html

Fernández Lagunilla, M. (I99I). La lengua en la comunicación politica I: El discurso del poder. Madrid: Arco Libros.

Fuentes Rodríguez, C. (20II). Argumentación, (des)cortesía y género en el discurso parlamentario. Tonos Digital. Revista de estudios filológicos 25. Accesible en http://www.um.es/tonosdigital/znum25/secciones/estudios-I Iccatalina_fuentes,_(2013,_tonos_25).htm

García Agustin, Óscar (2015). Podemos som postkrise-parti: Mellem populisme og radikalisme. Arbejderhistorier I, 34-57.

Halmari, H. y Virtanen, T. (eds.) (2005). Persuasion Across Genres. A linguistic approach. John Amsterdam/Philadelphia: Benjamins Publishing Company. 59-IO2. 
Hernández Flores, N. (20I3). Actividad de imagen: caracterización y tipología en la interacción comunicativa. Sociocultural Pragmatics. An International Journal of Spanish Linguistics. Vol I, Issue 2, I75-I98. https://doi.org/ IO.I 5 I 5/soprag-20I 2-00I 2

Hernández Flores, N. (20I4). "Imagen individual, imagen de grupo y la imagen de los otros en la construcción de una identidad política: el discurso del candidato español Pablo Iglesias." Workshop Political discourse in romance speaking countries: linguistic and social science perspecitives (ROMPOL I), I9-2I/Io/20I4. Universidad de Estocolmo.

Kaul de Marlangeon, S. (2003). [1992] "La fuerza de la cortesía-descortesía y sus estrategias en el discurso tanguero de la década del '20." Programa EDICE. Publicación electrónica www.edice.org. I-27.

Kaul de Marlangeon, S. (2005). "Descortesía intragrupal-crónica en la interacción coloquial de clase media-baja del español rioplatense”. En Murillo Medrano, J. (ed.), Actas del II Coloquio del Programa EDICE. I65-I79.

Kaul de Marlangeon, S (2008). "Tipología del comportamiento verbal descortés en español”. En Briz, A. et al. (eds.), Actas del III Coloquio Internacional del Programa EDICE Cortesía y conversación: de lo escrito a lo oral. Valencia, 2008.

Kienpointner, M. (1997). "Varieties of rudeness. Types and functions of impolite utterances." Functions of Language 4:2, $25 \mathrm{I}-287$.

Kienpointner, M. (2008). "Impoliteness and emotional arguments." Journal of Politeness Research 4, 243-265.

Pérez Vicente, N. (2013). "El lenguaje político del I 5-M: Hacia una nueva retórica de la indignación.” Signa 22, 569-594.

Pons, S. (20I4). "Blog. El lenguaje (Des)de la crisis.” https://www.lavozdegalicia.es/noticia/opinion/20I4/06/o2/friki/o003_201406G2PI4993.htm

Van Dijk, T. A. (2003). Ideología y discurso. Barcelona: Ariel.

\section{Apéndice.}

\section{El populismo}

Esperanza Aguirre. I4 de julio de 20I4. Publicado este lunes I4 de julio en La Quinta de ABC http://esperanza.ppmadrid.es/el-populismo/ [recuperado el I 4 de diciembre de 20I8]

El escritor suizo Friedrich Dürrenmat acertó plenamente cuando dijo: «Tristes tiempos estos en los que hay que luchar por lo que es evidente». Estas palabras me vienen a la cabeza cada vez que tengo que 
enfrentarme dialécticamente a adversarios políticos que defienden posiciones, ideas o doctrinas que hace ya muchos años que la Historia ha descalificado.

Esto me está ocurriendo últimamente con Podemos, sus mensajes, sus ideas y sus propuestas. Algunos, entre los que parece que hay bastantes personas de izquierda, e incluso algunas de derecha, dicen que Podemos es un partido nuevo que puede traer soluciones innovadoras para los graves problemas que España tiene hoy planteados.

Es verdad que en España la clase política está hoy desacreditada. Y también es verdad que, en muchos países donde se da este descrédito, surgen partidos que declaran que ellos son los únicos verdaderamente limpios y que proponen soluciones aparentemente muy sencillas para todos los problemas difíciles. A estos partidos se les suele agrupar bajo la etiqueta de "populistas». Porque lo que hacen es excitar los sentimientos más inmediatos del pueblo en dos direcciones. Primero, desprecian, insultan y vituperan a los partidos existentes. Y después, se presentan como los salvadores de la patria a base de proponer a los ciudadanos soluciones muy simplistas, que explican el mundo como si fuera una película de buenos y malos. Los «buenos», naturalmente, son ellos. Y los «malos», también naturalmente, los que no piensan como ellos.

Si los populistas hacen eso con habilidad y usan los adecuados mecanismos de propaganda, pueden tener éxito. Y, a veces, mucho éxito. La ascensión al poder de Hitler es un ejemplo bastante perfecto de este proceso. La Alemania de los años treinta estaba inmersa en una profundísima crisis económica, los partidos políticos de la República de Weimar no eran capaces de solucionar la crisis y se perdían en constantes querellas entre ellos, y por último, pero muy importante, Hitler contaba con Goebbels, que era un genio de la propaganda política.

Sin llegar a extremos tan dramáticos como el de Alemania, podemos encontrar procesos parecidos en muchos otros países. Sin ir más lejos ahora mismo los estamos contemplando, con más o menos variaciones, en algunos países hispanoamericanos.

No importa que todo lo que dicen los populistas sea mentira. No importa que no sean partidos para nada nuevos, sino representantes de tradiciones políticas muy antiguas y fracasadas. Como tampoco importa que sus soluciones no hayan solucionado nunca ningún problema allá donde se han aplicado. Basta con que consigan que haya gente que se lo crea. Y siempre puede haber quien lo haga. Incluso, de buena fe. 
Porque se dan algunas de las condiciones para la aparición de un partido de estas características es por lo que ha surgido en España Podemos. Estamos inmersos en una crisis económica muy profunda que ha mandado al paro a millones de ciudadanos, que les ha empobrecido y que ha disminuido de una forma tremenda las oportunidades de todos y, sobre todo, de los jóvenes. Al mismo tiempo, la confianza en los partidos tradicionales se ha colocado bajo mínimos. Y, además, los políticos de Podemos han demostrado conocer muy bien las técnicas de propaganda que crearon y desarrollaron en los años treinta Willy Münzenberg y Joseph Goebbels. Münzenberg y Goebbels eran alemanes, los dos eran más o menos de la misma edad, los dos fueron unos genios de la maldad, los dos acabaron mal, y los dos tienen una importante cuota de responsabilidad en el triunfo de las dos ideologías más nefastas de la Historia: el comunismo y el nazismo.

La aparición de Podemos, si algo hemos aprendido de la Historia, no es tan sorprendente. Lo que sí puede ser imperdonable es que en España los que sabemos de los peligros de este tipo de movimientos reaccionemos con la irresponsabilidad con que lo hicieron los que, en Argentina, decían "Cristina no tiene carisma", o, en Ecuador, "Correa es una anécdota irrelevante», o, en Venezuela, «a Chávez, en cuanto toque poder, se lo come Estados Unidos».

Y eso puede ocurrir si creemos que los argumentos demagógicos, simplistas y falaces que utilizan los de Podemos se descalifican solos. Eso puede ocurrir si nos da pereza debatir con ellos porque consideramos que sus argumentos están absolutamente desprestigiados por la Historia. Porque, efectivamente, da mucha pereza tener que demostrar que el comunismo, del que los de Podemos se declaran hijos, sólo ha traído crimen y miseria allá donde se ha aplicado. Pero hay que hacerlo. Como hay que insistir en que cuando Iglesias afirma que «el terrorismo de ETA tiene explicaciones políticas» está utilizando los mismos falaces argumentos de los etarras para justificar sus 858 asesinatos. Porque, desde hace casi cuarenta años, en España existen cauces democráticos para defender todas las posiciones políticas. Y nada podrá justificar nunca esos asesinatos. También hay que denunciar que utiliza los argumentos de los etarras cuando llama "papelito» a la Constitución de I978, la que, precisamente, le garantiza a él y a todos nuestros derechos. O cuando desprecia a todas las fuerzas políticas democráticas de los últimos cuarenta años y tiene el desparpajo de afirmar que solo la izquierda vasca y ETA se dieron cuenta de que esa Constitución no instaura unas reglas del juego democráticas. 
Puede ser muy cansado y aburrido tener que discutir argumentos tan simples y mentirosos, pero hay que hacerlo.

No se nos pueden olvidar nunca los versos de Yeats, el gran poeta irlandés que tuvo el Premio Nobel: "The best lack all conviction, while the worst / Are full of passionate intensity». ( «Los mejores carecen de toda convicción, mientras que los peores están llenos de una intensidad apasionada»). Nosotros, los que amamos la libertad y sabemos de los peligros de la demagogia populista, también tenemos que demostrar que estamos llenos de esa apasionada intensidad. 